\title{
CORRESPONDENCE
}

\section{Pick sanitation over vaccination in Haiti}

I have been investigating Haiti's water system since 2007 and strongly believe that the limited resources available to combat the country's cholera epidemic should be spent on sanitation and clean water, rather than on vaccination (Nature 469, 273-274; 2011). Otherwise, the local geology and ecology will allow cholera and other waterborne pathogens to persist.

Haiti has a backbone of granitic igneous rocks near the border with the Dominican Republic, surrounded by sedimentary limestone and shale. Fissures in limestone give rise to shallow aquifers that are especially prone to contamination by water-borne pathogens.

The devastation of last year's earthquake in Haiti joined intractable problems of poverty, deforestation and the loss of its microbiotic ecosystem. Soil microorganisms that consume pathogens are integral to the macrobiotic ecosystem, and are a first line of defence against groundwater contamination. The loss of Haiti's soils and the beneficial organisms they host means that many shallow aquifers are now unprotected.

Pathogens that thrive in Haiti's warm groundwater are flushed out by heavy rains and hurricanes, helping them to spread and cause new disease outbreaks. This is why funds should be spent on long-term, sustainable and resilient water resources.

Peter Wampler Grand Valley State University, USA. wamplerp@gvsu.edu

\section{Harnessing value of dispersed critiques}

You mention the 'publish and be damned' model in academia, in which scientific work is disseminated, regardless of merit, for rapid and public online criticism rather than slow, private peer review (Nature 469 , 286-287; 2011). For this to work, we must devise new ways to link widespread Internet discussions to and from an original paper.

Under current academic publishing models, one could easily miss substantive reactions to a paper that appear in other peer-reviewed journals. Even when a paper is retracted, research shows that this information is poorly disseminated and that the paper can continue to be cited widely and positively for years afterwards (K. M. Korpela Curr. Med. Res. Opin. 26, 843-847; 2010).

The growth of blogs, Twitter and free online access have caused a welcome explosion in scientific content. But this is atomized and interconnected by a hotchpotch of linking and referencing conventions. If we are going to harness its true value, we shall need dedicated librarians and information scientists to find ways of automating the process of linking content together again. That in itself would be a transgressive scientific innovation.

Ben Goldacre London School of Hygiene and Tropical Medicine, UK.

ben.goldacre@lshtm.ac.uk

\section{Biomarkers: better donor protection}

George Poste calls for the creation of international biobanks as part of research efforts on disease and drug-response biomarkers (Nature 469, 156-157; 2011). As the director of Israel's biobank and a member of international biobank organizations, I must point out that this can only work if the use of genetic information is guaranteed to be non-discriminatory.
Laws that guard against such discrimination are essential for public trust in biomedical research and to protect the identity of donors, but few countries have laws in place that are sufficiently comprehensive - including the United States (R. Korobkin and R. Rajkumar N. Engl. J. Med. 359, 335-337; 2008).

The need to safeguard genetic information is becoming more urgent. For example, personal sequence data sent over the Internet by direct-to-consumer providers are insufficiently protected; and biobank donors or customers who are protected in their home country may still face discrimination by employers or insurers in another. Such concerns risk discouraging potential donors and will hinder international biobanking efforts.

Calls to issue a genetic information non-discrimination amendment to the Helsinki Declaration of Human Rights have been voiced for some time (J. Harris and J. Sulston Nature Rev. Genet. 5, 796-800; 2004). That might not solve all biobanking problems, but it could improve the international situation. The grim statistics on the poor yield of clinically valuable biomarkers serve as a sober reminder that the time has come for such an amendment. David Gurwitz Tel-Aviv

University, Israel.

gurwitz@post.tau.ac.il

\section{Biomarkers: call on industry to share}

It will be challenging to mobilize public funding for huge standardized repositories of biological specimens and accompanying clinical data (Nature 469, 156-157; 2011). But this could be complemented by tapping into ongoing industry-sponsored biobanking activities.

For example, clinical trials often include dedicated biomarker studies, with a budget for collecting specimens and data - a facility that could contribute to shared repositories, serving both industry and the public at a modest additional public cost. Even if only a fraction of the more than four million subjects enrolled worldwide in interventional trials were to be captured, progress would be enormous.

From my work on biomarker detection at biotechnology company SDIX, and as a consultant on biobanking for public-health authorities, it is clear that this expansion could also advance public health, providing biomarkers to improve our understanding of risk factors associated with populationspecific diseases and helping us to tailor public-health initiatives.

Such a synergistic venture could significantly advance the field, but would require systematic encouragement from national health ministries, harmonization of protocols, integration of individual repositories into larger virtual networks, attention to ethical, legal and social implications, and respect for the need of private partners to retain certain intellectual-property rights. Klaus Lindpaintner Strategic Diagnostics (SDIX), USA. klindpaintner@sdix.com

CONTRIBUTIONS

Correspondence may be submitted to correspondence@nature. com after consulting the author guidelines at http:// go.nature.com/cmchno. Readers are also welcome to comment online on anything published in Nature: www.nature.com/ nature. 